\title{
Three-Dimensional Image Contribution for Evaluation of Operative Procedural Errors in Endodontic Therapy and Dental Implants
}

\author{
Julio Almeida SILVA \\ Ana Helena Gonçalves de ALENCAR \\ Sicknan Soares da ROCHA \\ Lawrence Gonzaga LOPES \\ Carlos ESTRELA
}

Dental School, UFG - Federal University of Goiás, Goiânia, GO, Brazil

\begin{abstract}
Acceptable therapeutic protocol in dentistry depends on the outcomes obtained with follow up. Operative procedural errors (OPE) may occur and they represent risk factors able to compromise a tooth or a dental implant. The aim of this study was to detect the OPE in endodontically treated teeth and dental implants, using cone beam computed tomography (CBCT). Eight hundred and sixteen CBCT exams were performed between January 2009 and October 2010, and only those which presented endodontically treated teeth and/ or dental implants were selected. The sample was as follows: 195 CBCT exams ( $\mathrm{n}=200$ teeth and 200 dental implants), 72 male, 123 female, with mean age of 51 years. In endodontically treated teeth, OPE included underfilling, overfilling, and root perforation; OPE in dental implants were thread exposures, contact with anatomical structures, and contact with adjacent teeth. Kolmogorov-Smirnov test was used for statistical analysis, with significance level set at $\alpha=0.05$. Underfilling, overfilling, and root perforations were detected in $33.5 \%, 8 \%$ and $4.5 \%$ of the teeth, respectively. Dental implants with thread exposures, contact with important anatomical structures and contact with adjacent teeth were seen in $37.5 \%, 13 \%$ and $6.5 \%$ of the cases, respectively. OPE were detected in endodontically treated teeth and dental implants, and underfilling and thread exposures were the most frequent occurrences, respectively.
\end{abstract}

Key Words: endodontic failure, dental implant failure, cone beam computed tomography, diagnostic imaging.

\section{INTRODUCTION}

The periapical tissue health and the maintenance of the tooth in the oral cavity are the main goal of endodontic therapy. Another alternative to replace the compromised tooth is dental implant-based restoration (1). However, both Endodontics and Implantology are challenging considering the technical difficulties, professional ability and scientific knowledge in both areas.

Clinical radiographic criteria of therapeutic success have been considered important to establish a clinical decision in both specialties. In endodontically treated teeth the success includes absence of pain and swelling; absence of drainage and fistula; tooth in function, with normal physiology; disappearance of periapical bone rarefaction (2).
The clinical condition after rehabilitation treatment with dental implants might be determined with an implant quality scales. Success (optimum health) is considered when the patient does not report pain or tenderness upon function, absence of mobility, radiographic bone loss initial surgery less than $2 \mathrm{~mm}$, and no exudate history. Satisfactory survival includes no pain upon function, absence of mobility, radiographic bone loss between 2-4 mm, and no exudate history. In situations of compromised survival there may be sensitivity on function, absence of mobility, radiographic bone loss greater than $4 \mathrm{~mm}$ (less than half of implant body), probing depth greater than $7 \mathrm{~mm}$ and no exudate history, and there may be exudates history. Clinical or absolute failure is characterized by pain on function, mobility, radiographic bone loss greater than half the length of implant, uncontrolled exudate, and no longer

Correspondence: Prof. Dr. Carlos Estrela, Departamento de Ciências Estomatológicas, Universidade Federal de Goiás, Praça Universitária S/N, Setor Universitário, 74605-220 Goiânia, GO, Brasil. Tel: +55-62-3016-2121. e-mail: estrela3@terra.com.br 
in the mouth (3).

The assessment of dental treatment by computed tomography represents an expressive advance of information in health studies and contributes in planning, diagnosis, therapeutic process and prognosis of several diseases. The continuous advance of technology enabled the development of cone beam computed tomography (CBCT) $(4,5)$, which had shown numerous perspectives for applications in different research areas and clinical dentistry (4-9). Imaging resources routinely had been used before, during and after dental management. Conventional radiographic images provide a twodimensional rendition of a three-dimensional structure, which may result in interpretation errors. Periapical lesions of endodontic origin may be present but not visible on conventional 2D radiographs $(2,6,7)$. Diagnostic accuracy is critical for treatment success. The correct management of CBCT images might reveal abnormality that is unable to be detected in periapical radiography and may favor more predictable planning and treatment. A possibility of map-reading approach with CBCT images reduces problems related to difficult evaluation conditions which require special care during diagnosis (8).

CBCT scans provide detailed high-resolution images of oral structures and permit early detection of alterations in maxillofacial structures. This technology allows the determination of linear distances and volume of anatomic structures, pre-surgical planning of maxillofacial lesions, root length and marginal bone level during orthodontic treatment, reconstruction techniques, bone level changes following regenerative periodontal therapy, periodontal defect, periapical lesions, and root resorptions (6-9).

Operative procedural errors (OPE) are caused by several factors inherent to patient and/or professional, and their consequences may influence on prognosis. Alencar et al. (10) assessed OPE (fractured instruments, perforations and apical transportation) created by rotary NiTi instruments during root canal preparation by using $\mathrm{CBCT}$, and observed that this imaging method offered more resources for diagnosis.

Endodontic therapy or placement of a dental implant requires planning, knowledge and an accurate operative ability. OPE characterize disability, nonobservance of therapeutic protocol and low level of knowledge involving endodontic and dental implant principles. Deficient attendance may be responsible for severe consequences and sequels, which impairs the prognosis, and may be responsible for serious judicial questions.

The dilemma of replacing a biological structure by biocompatible material requires care, information about criteria and rates of success in endodontically treated teeth and dental implants. Thus, viewing the lack of studies comparing the outcome between endodontic therapy with dental implants and the limitations in its longitudinal interpretations showed the need of researches using a more accurate tool. The potential of CBCT as diagnosis imaging method justifies this investigation. The aim of this cross-sectional study was to detect OPE in endodontically treated teeth and dental implants, using CBCT.

\section{MATERIAL AND METHODS}

The study was structured using databases of private radiology clinics (Centro Integrado de Radiologia, C.I.R.O., Goiânia, GO, Brazil). The patients were referred to the dental radiology service for different diagnostic purposes. Eight hundred and sixteen CBCT exams were performed between January 2009 and October 2010, and only those which presented endodontically treated teeth and/or dental implants were selected. The sample was as follows: $195 \mathrm{CBCT}$ exams $(\mathrm{n}=200$ teeth and 200 dental implants), 72 male, 123

Table 1. Distribution of operative procedural errors in endodontically treated teeth.

\begin{tabular}{lccccc}
\hline Region & $\mathrm{N}=200$ & Underfilling & Overfilling & Root perforation & Significance level \\
\hline Anterior maxilla & $75(37.5 \%)$ & $12(6 \%)$ & $9(4.5 \%)$ & $3(1.5 \%)$ & $\mathrm{p}>0.05$ \\
Posterior maxilla & $85(42.5 \%)$ & $42(21 \%)$ & $3(1.5 \%)$ & $5(2.5 \%)$ & $\mathrm{P}<0.05$ \\
Anterior mandible & $3(1.5 \%)$ & $3(1.5 \%)$ & $0(0 \%)$ & $0(0 \%)$ & $\mathrm{p}>0.05$ \\
Posterior mandible & $37(18.5 \%)$ & $10(5 \%)$ & $4(2 \%)$ & $1(0.5 \%)$ & $\mathrm{p}>0.05$ \\
Total & $200(100 \%)$ & $67(33.5 \%)$ & $16(8 \%)$ & $9(4.5 \%)$ & $\mathrm{p}<0.05$ \\
\hline
\end{tabular}


female, with mean age of 51 years. The study design was approved by the institutional Ethics Committee (UFG, Process \#169/2008).

Inclusion criteria for both groups included all CBCT exams with one or more teeth with history of endodontic treatment, and one or more dental implants. Only images with high-resolution quality and absence of metallic artifacts that could impair an accurate analysis were considered. It was considered the number of teeth or dental implants associate with OPE.

\section{Imaging Analysis}

CBCT images were acquired with the firstgeneration i-CAT Cone Beam 3D imaging system (Imaging Sciences International, Hatfield, PA, USA). The volumes were reconstructed with isotropicisometric voxels measuring $0.20 \mathrm{~mm} \mathrm{X} 0.20 \mathrm{~mm} X$ $0.20 \mathrm{~mm}$. The tube voltage was $120 \mathrm{kVp}$ and the tube current $36.12 \mathrm{~mA}$. Exposure time was $40 \mathrm{~s}$. Images were examined with the scanner's proprietary software (Xoran version 3.1.62; Xoran Technologies, Ann Arbor, MI, USA) in a PC workstation running Microsoft Windows XP professional SP-2 (Microsoft Corp., Redmond, WA, USA), with processor Intel Core 2 Duo-6300 $1.86 \mathrm{Ghz}$ (Intel Corporation, Santa Clara, CA, USA), Nvidia GeForce 6200 turbo cache videocard (NVIDIA Corporation, Santa Clara, CA, USA) and Monitor Eizo - Flexscan S2000, resolution 1600x1200 pixels (Eizo Nanao Corporation, Hakusan, Japan).

All CBCT scans were analyzed by two investigators (endodontists and dental radiologists, both with 5 or more years of experience), who were calibrated by reexamining $10 \%$ of the sample; when differences were noted, a consensus was reached, discussing the image with a third examiner.

The examiners evaluated the images to determine the following OPE in endodontically treated teeth: underfilling (the filling material with more $2 \mathrm{~mm}$ short of the root apex); presence of overfilling (the filling material beyond apex), and root perforation. The analysis of OPE in dental implants regarded: thread exposures more than $1 / 3$ of the implant body (outside of the alveolar bone), dental implants in contact with important anatomical structures (mandibular canal, mental foramen or incisive foramen, and dental implants with more than $1 / 3$ of the body invading maxillary sinus or nasal cavity), contact with the adjacent teeth.

\section{Statistical Analysis}

Kolmogorov-Smirnov test was used for statistical analysis, and the significance level was set at $\alpha=0.05 \%$.

\section{RESULTS}

The distribution of the 200 endodontically treated teeth examined by CBCT was as follows: upper anterior region, $n=75$; upper posterior region, $n=85$; lower anterior region, $\mathrm{n}=3$; lower posterior region $\mathrm{n}=37$. Underfilling, overfilling, and root perforation were detected in $33.5 \%, 8 \%$ and $4.5 \%$ of the teeth, respectively (Table 1 ).

The distribution of the 200 dental implants examined by $\mathrm{CBCT}$ was as follows: upper anterior region, $\mathrm{n}=67$; upper posterior region, $\mathrm{n}=65$; lower anterior region, $n=8$; lower posterior region $n=60$. Dental implants with exposed threads, contact with important anatomical structures and contact with adjacent teeth were detected in $37.5 \%, 13 \%$ and $6.5 \%$ of the cases, respectively (Table 2).

OPE in endodontically treated teeth and dental implants, detected in CBCT coronal, sagittal and axial slices are illustrated in Figures 1 and 2.

Table 2. Distribution of operative procedural errors in dental implants.

\begin{tabular}{|c|c|c|c|c|c|}
\hline Region & $\mathrm{N}=200$ & $\begin{array}{c}\text { Thread } \\
\text { exposures }\end{array}$ & $\begin{array}{l}\text { Contact with } \\
\text { anatomical structures }\end{array}$ & $\begin{array}{l}\text { Contact with } \\
\text { adjacent teeth }\end{array}$ & $\begin{array}{c}\text { Significance } \\
\text { level }\end{array}$ \\
\hline Anterior maxilla & $67(33.5 \%)$ & $40(20 \%)$ & $6(3 \%)$ & $8(4 \%)$ & $\mathrm{p}<0.05$ \\
\hline Posterior maxilla & $65(32.5 \%)$ & $18(9 \%)$ & $4(2 \%)$ & $12(6 \%)$ & $\mathrm{p}>0.05$ \\
\hline Anterior mandible & $8(4 \%)$ & $1(0.5 \%)$ & $0(0 \%)$ & $2(1 \%)$ & $\mathrm{p}>0.05$ \\
\hline Posterior mandible & $60(30 \%)$ & $16(8 \%)$ & $3(1.5 \%)$ & $4(2 \%)$ & $\mathrm{p}<0.05$ \\
\hline Total & $200(100 \%)$ & $75(37.5 \%)$ & $13(6.5 \%)$ & $26(13 \%)$ & $\mathrm{p}<0.05$ \\
\hline
\end{tabular}




\section{DISCUSSION}

Root canal therapy and dental implant placement involve an important discussion in dentistry. The extension of treatment for a tooth condemned to extraction can be a dental implant. The detection of OPE in endodontically treated teeth and dental implants is medically controversial and complex, due to limitations of periapical and panoramic radiography. The value of periapical radiography to identify the quality of endodontically treated teeth and the position of the dental implants is recognized. However, despite the benefits, this conventional imaging method has limitations, mainly the image overlapping and the need for extensive bone loss to display the rarefaction image $(6,7)$.

The possibility of evaluating endodontically
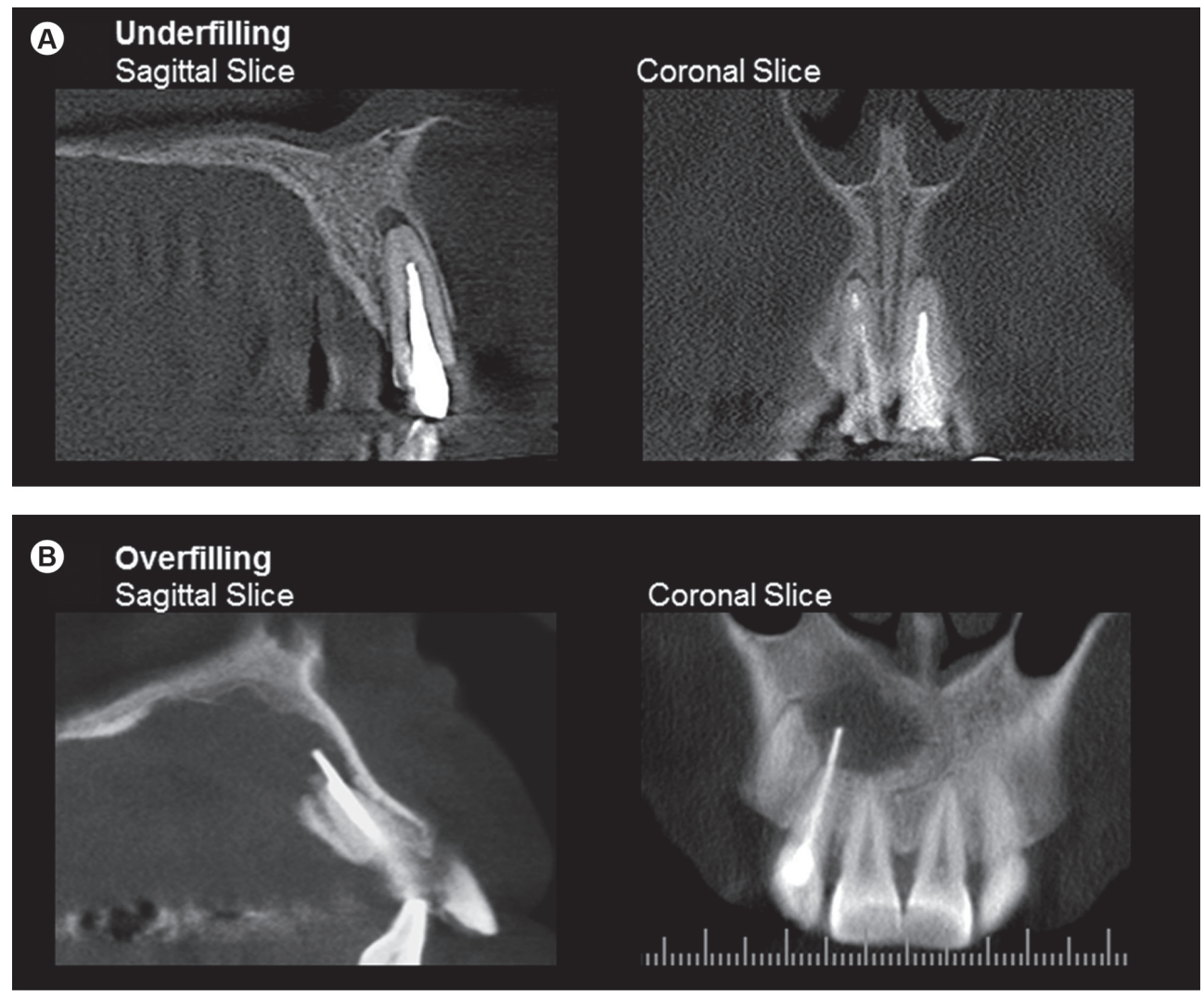

\section{Root perfuration Sagittal Slices}

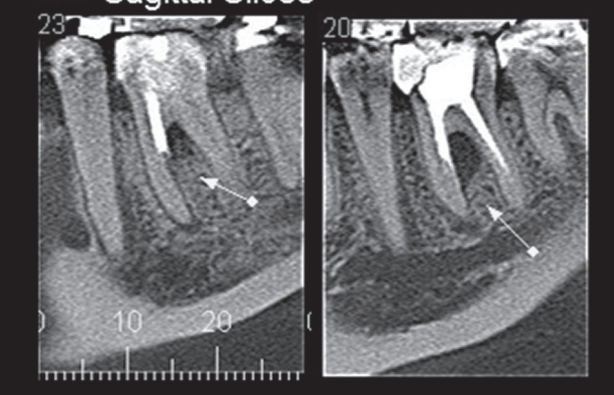

Coronal Slices

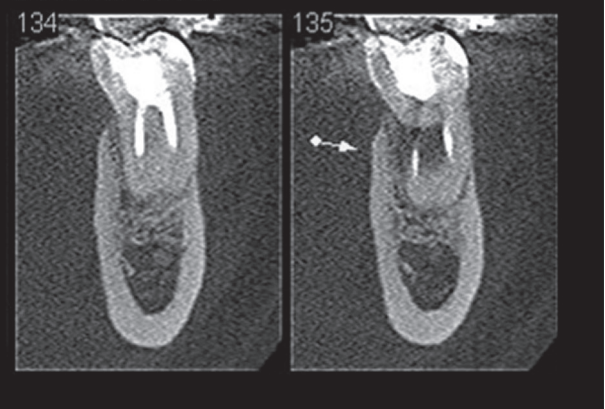

Figure 1. Operative procedural errors in endodontically treated teeth. A: Sagital and coronal slices of maxillary central incisor with underfilling showing periapical radiolucency, B: Sagittal and coronal slices of maxillary lateral incisor with overfilling associated with extensive periapical radiolucency, C: Sagittal and coronal slices of mandibular molar with root perforation. 
treated teeth and dental implants using CBCT increases the potential for evaluating the therapeutic protocol. CBCT scans give the possibility of a reading by mapping, with the acquisition of valuable information through a dynamic display in different planes (6-8). It has been shown a greater accuracy in the diagnosis of apical periodontitis when using CBCT compared with conventional radiography $(6-9,11)$.

The formation of artifacts, especially near bodies of high density, such as metal pieces (intraradicular
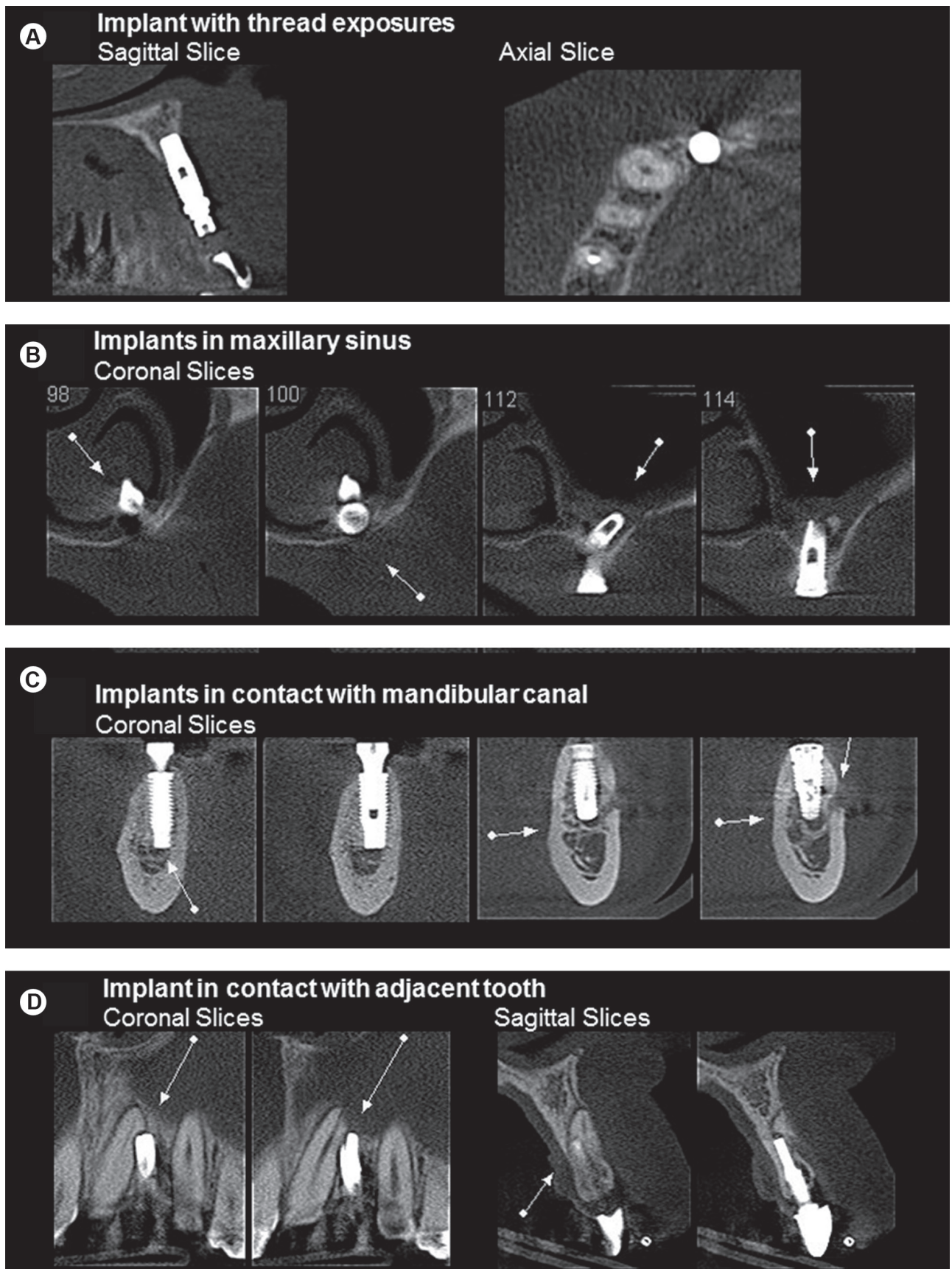

Figure 2. Operative procedural errors in dental implants. A: Sagittal and axial slices of dental implant in maxillary anterior region with thread exposures in buccal and palatal faces, B: Coronal slices of dental implant in posterior maxillary region with more than $1 / 3$ body in maxillary sinus, $\mathrm{C}$ : Coronal slices of dental implant in posterior mandibular region in contact with mandibular canal, D: Coronal and sagittal slices of dental implant in anterior maxillary region in contact with the adjacent tooth. 
cores, crowns and metal restorations), requires care during $\mathrm{CBCT}$ imaging to avoid misdiagnosis. In this study, the CBCT images were analyzed by a specialist in Endodontics and a specialist in Dental Radiology, with expertise in thee-dimensional tracking and prepared to identify technical artifacts.

Kojima et al. (12) determined the influence of factors such as apical limit, and pulpal and periapical status on endodontic prognosis using a meta-analysis. Root canal filling within $2 \mathrm{~mm}$ of the radiographic apex appeared as the best prognosis. This fact was considered as a justification for the presence of underfilling more than $2 \mathrm{~mm}$ short of the root apex.

The results of this study to detect OPE at endodontically treated teeth, through CBCT imaging, showed $33.5 \%$ of underfillings, $8 \%$ of overfillings and $4.5 \%$ root perforations. These results are similar to those of Moura et al. (13), which found $10 \%$ of overfillings in anterior teeth, and those of Alencar et al. (10), in which root perforations were detected in 5\% (6/120) of the endodontically treated root canals, both using CBCT imaging. In contrast, when conventional radiography was used as a diagnostic method, Santos et al. (14) observed $0.37 \%$ of roots with perforations and $2.67 \%$ of roots with overfilling. This divergent results illustrate the difficulty in comparing studies using different criteria and tools for image analysis.

In the present study, occurrence of underfilling was detected in upper posterior teeth, reaching $21 \%$ (Table 1), although inadequate fillings (76.3\%) in posterior teeth were verified by Moussa-Badran et al. (15).

Epidemiological studies conducted in different population groups have reported differences between the percentages of inadequate root canal filling (16). This variation can be attributed to the level of training of operator - students, general dentists, graduate students and specialists - plus the length of experience.

The occurrence of dental implants with exposed threads, in contact with important anatomical structures and in contact with adjacent teeth reached $37.5 \%, 13 \%$ and $6.5 \%$, respectively, in this investigation. The upper front teeth had a greater frequency of dental implants with exposed threads.

The literature is scarce in studies using CBCT to assess OPE in dental implants. However, there is research that established the prognosis of dental implants from radiographic signs (17). The radiographic examination remains an important tool to identify failure in dental implants in clinical practice. The essential factors for proper evaluation of the condition of the implant is the quality of radiograph combined with experience of the examiner (18). A sequence of longitudinal standardized radiographs are required to measure changes in interproximal bone level and detect periimplant radiolucencies. The radiographic image of periimplant radiolucency suggests no direct contact with bone/implant and the possibility of loss of stability. However, there may be marginal bone loss and implant remains stable (19).

OPE represent risk factors that can affect one tooth or a dental implant. A well-structured clinical protocol of treatment favors the survival conditions for an endodontically treated teeth or a dental implant. The success or failure are important parameters to indicate and maintain an appropriate therapeutic protocol. However, distinct clinical and radiographic criteria have been used to evaluate success rates in different studies, making it impossible to compare results.

Torabinejad and Babjri (20), discussed about dental treatment based on evidences. Few high-level studies have been published in the last four decades, related to success and failure of endodontic treatment. Radiographic analysis has been highlighted as a limitation on longitudinal clinical studies because it is subject to personal interpretation; change in angulation, which can give a completely different look to injury, making it appear smaller or larger; and clinical symptoms such as presence of pain, fistula or swelling that can occur without radiographic evidence of bone destruction. Estrela et al. (7) reported the high accuracy of CBCT compared with periapical and panoramic radiography in the detection of apical periodontitis. Wu et al. (12), showed that a high percentage of endodontically treated teeth presenting aspects of normality in radiographs were revealed with apical periodontitis by $\mathrm{CBCT}$ and histological examination. Therefore, the results of epidemiological studies of success rates in endodontic treatments should be reassessed with more stringent criteria, on a long-term basis, and using more accurate tools such as CBCT (12).

Implantology has developed new research results that provide better knowledge of biological principles of dental implant (21). The criteria used for analysis of success in endodontically treated teeth have been more stringent than those applied to treatments with dental implants (20). The parameters used to evaluate the failure of dental implants have been clinical signs 
of infection, increased mobility and radiographic signs of bone loss, taking from them the distinction between "failed" implant and "failing" implant (21). There has been a great deal of heterogeneity in studies considering the duration of follow up, success criteria, type of dental implant, and loading time of implant (22).

The relationship between failure rates of endodontic treatments and treatments with dental implants has been emphasized in some contemporary studies $(23,24)$. Schmidlin et al. (23), demonstrated a greater long-term survival and higher success rates for single crowns in teeth with vital pulp in comparison with single crowns in endodontically treated teeth or on dental implants. Metal ceramic crown at endodontically treated teeth with fused pin lead to lower survival rates in 10 years. Despite the dental implants have high rates of survival, they required subsequent treatment. Similar results had been found by Hannahan and Eleazar (24) regarding the need for postoperative treatments to keep the dental implant in the oral cavity under appropriate conditions, although the success rates of dental implants versus root canal treatment have been proven essentially identical.

When the survival rate (teeth in function with or without radiographic lesion) for endodontically treated teeth is used, instead of the traditional criteria, the success rate of the teeth treated endodontically by a specialist is equal to or greater than the success of dental implants in long-term (25).

Iqbal and Kim (22) discussed the factors that influence the decision to treat with dental implants versus preservation of endodontically treated teeth. They concluded that dental implants are useful alternatives for tooth replacement that cannot be treated with good prognosis. However, dental implants cause pain and inflammation, are about twice more expensive than endodontic treatment, are associated with extensive interventions post treatment and they do not have better survival rates than teeth that are root filled and restored.

A discussion on contemporary dentistry is the selection of treatment for severely compromised teeth. The role of treatment with dental implant in patients with involved teeth has remained uncertain, controversial and subject of considerable debates. Not only the choice of treatment, but also the criteria that define the tooth as compromised are controversial and subject to different interpretations. Therefore, a careful consideration of the indications and contra-indications, risks and benefits of dental implants and endodontic treatment is critical for success. An accurate evaluation of treatment options should be presented to the patients for their informed consent prior to making a decision of the treatment (22).

OPE are risk factors that might contribute to failure of endodontic therapy and dental implant placement. Knowledge of these errors suggests the need for greater care during the planning and execution of operative procedures.

\section{RESUMO}

Protocolos terapêuticos aceitáveis em odontologia dependem de resultados observados com a proservação. Erros de procedimentos operatórios podem ocorrer e representam fatores de risco capazes de comprometer um dente ou um implante dentário. O objetivo deste artigo é detectar os erros de procedimentos operatórios em dentes tratados endodonticamente e implantes dentários por meio de tomografia computadorizada de feixe cônico. Oitocentos e dezesseis (816) exames tomográficos foram realizados entre Janeiro de 2009 e Outubro de 2010, e apenas aqueles que apresentaram dentes tratados endodonticamente e/ou implantes dentários foram selecionados. A amostra final envolveu 195 exames tomográficos ( $\mathrm{n}=200$ dentes e 200 implantes dentários), 72 do gênero masculino, 123 do gênero feminino, com idade média de 51 anos. Em dentes tratados endodonticamente os erros de procedimentos operatórios incluídos foram: subobturação, sobreobturação, e perfuração radicular; enquanto que, para implantes dentários foram incluídos: roscas de implantes expostas, implantes em contato com estruturas anatômicas, e em contato com dentes adjacentes. O nível de significância foi estabelecido em $\alpha=5 \%$. Subobturações, sobreobturações e perfurações radiculares foram detectadas em $33,5 \%, 8 \%$ e $4,5 \%$, respectivamente. Implantes dentários com roscas expostas, em contato com estruturas anatômicas, e em contato com dentes adjacentes apresentaram valores de $37,5 \%, 13 \%$ e $6,5 \%$, respectivamente. Erros de procedimentos operatórios foram detectados em dentes tratados endodonticamente e implantes dentários. Os erros mais frequentes foram subobturação em dentes tratados endodonticamente, e roscas expostas em implantes dentários.

\section{ACKNOWLEDGEMENTS}

This study was supported in part by grants from the National Council for Scientific and Technological Development (CNPq) - grant \#306394/2011-1 to C.E.

\section{REFERENCES}

1. Riccuti D, Grosso A. The compromised tooth: conservative treatment or extraction? Endod Topics 2006;13:108-122.

2. Bender IB. Factors influencing the radiographic appearance of bone lesions. J Endod 1982;8:161-170.

3. Misch CE, Perel ML, Wang HL, Sammartino G, GalindoMoreno P, Trisi P, et al.. Implant success, survival, and failure: the International Congress of Oral Implantologists (ICOI) Pisa Consensus Conference. Implant Dent 2008;17:5-15.

4. Arai Y, Tammisalo E, Iwai K, Hashimoto K, Shinoda K. 
Development of a compact computed tomography apparatus for dental use. Dentomaxillofac Radiol 1999;28:245-248.

5. Mozzo P, Procacci C, Taccoci A, Martini PT, Andreis IA. A new volumetric $\mathrm{CT}$ machine for dental imaging based on the conebeam technique: preliminary results. Eur Radiol 1998;8:15581564.

6. Cotton TP, Geisler TM, Holden DT, Schwartz SA, Schindler WG. Endodontic applications of cone-beam volumetric tomography. J Endod 2007;33:1121-1132.

7. Estrela C, Bueno MR, Leles CR, Azevedo B, Azevedo JR. Accuracy of cone beam computed tomography and panoramic and periapical radiography for detection of apical periodontitis. $\mathrm{J}$ Endod 2008;34:273-279.

8. Bueno MR, Estrela C, Figueiredo JAP, Azevedo BC. Map-reading strategy to diagnose root perforations near metallic intracanal posts by using cone beam computed tomography. J Endod 2011;37:85-90.

9. Estrela C, Bueno MR, Azevedo BC, Azevedo JR, Pécora JD. A new periapical index based on cone beam computed tomography. J Endod 2008;34:1325-1333.

10. Alencar AHG, Dummer PHM, Oliveira HCM, Pécora JD, Estrela C. Procedural errors during root canal preparation using rotary NiTi instruments detected by periapical radiography and cone beam computed tomography. Braz Dent J 2010;21:543-549.

11. Wu M-K, Shemesh H, Wesselink PR. Limitations of previously published systematic reviews evaluating the outcome of endodontic treatment. Inter Endod J 2009;42:656-666.

12. Kojima K, Inamoto K, Nagamatsu K, Hara A, Nakata K, Morita I, et al.. Success rate of endodontic treatment of teeth with vital and nonvital pulps: a meta-analysis. Oral Surg Oral Med Oral Pathol Oral Radiol Endod 2004;97:95-99.

13. Moura MS, Guedes OA, Alencar AHG, Azevedo BC, Estrela C. Influence of length of root canal obturation on apical periodontitis detected by periapical radiography and conebeam computed tomography. J Endod 2009;35:805-809.

14. Santos SMC, Soares JA, César CAS, Brito-Júnior M, Moreira AN, Magalhães CS. Radiographic quality of root canal fillings performed in a postgraduate program in Endodontics. Braz Dent $\mathrm{J}$ 2010;21:315-321.
15. Moussa-Badran S, Roy B, Bessart du Parc AS, Bruyant M, Lefevre B, Maurin JC. Technical quality of root fillings performed by dental students at the dental teaching centre in Reims, France. Int Endod J 2008;41:679-684.

16. Kirkevang LL, Orstavik D, Horsted-Bindslev P, Wenzel A. Periapical status and quality of root fillings and coronal restorations in a Danish population. Int Endod J 2000;33:509-515.

17. Espósito M, Hirsch J-M, Lekholm U, Thomsen P. Biological factors contributing to failures of osseointegrated oral implants. (I) Success criteria and epidemiology. Eur J Oral Sci 1998;106:527551.

18. Gröndahl K, Lekholm U. The predictive value of radiographic diagnosis of implant instability. Int J Oral Maxillofac Implants 1997;12:59-64.

19. Brägger U. Radiographic parameters for the evaluation of periimplant tissues. Periodontol 2000 1994;4:87-97.

20. Torabinejad M, Bahjri K. Essential elements of evidenced-based Endodontics: steps involved in conducting clinical research. J Endod 2005;31:563-569.

21. Sakka S, Couthard P. Implant failure: etiology and complications. Med Oral Patol Oral Cir Bucal 2011;16:e42-e44.

22. Iqbal MK, Kim S. A review of factors influencing treatment planning decisions of single-tooth implants versus preserving natural teeth with nonsurgical endodontic therapy. J Endod 2008;34:519-529.

23. Schmidlin K, Schnell N, Steiner S, Salvi GE, Pjetursson B, Matuliene $\mathrm{G}$, et al.. Complication and failure rates in patients treated for chronic periodontitis and restored with single crowns on teeth and/or implants. Clin Oral Impl Res 2010;21:550-557.

24. Hannahan JP, Eleazer PD. Comparison of success of implants versus endodontically treated teeth. J Endod 2008;34:1302-1305.

25. Alley BS, Kitchens GG, Alley LW, Eleazer PD. A comparison of survival of teeth following endodontic treatment performed by general dentists or by specialists. Oral Surg Oral Med Oral Pathol Oral Radiol Endod 2004;98:115-118.

Received July 28, 2011

Accepted March 3, 2012 